\title{
Unruly bodies and couples' sleep
}

\author{
Robert Meadows $^{1}$, Sara Arber ${ }^{1}$, Susan Venn ${ }^{1}$ and Jenny Hislop ${ }^{2}$
}

\begin{abstract}
Everyday social order is said to be based on appropriate bodily conduct. The emphasis on day raises at least two questions for the sociological study of sleep: the first concerns the existence of a 'sleep habitus' and whether sleeping bodies can ever be 'unruly'. The second involves the possibilities for breaching or mediating any such 'sleep habitus'. What we suggest here is that any 'sleep habitus' does appear to be limited. If a sleeper is considered to be 'unconscious', in a private space, and in an intimate relationship with his or her audience, bodies appear free to do anything without invoking the need for embarrassment. However, at the same time, couples do suggest that sleeping bodies can feel embarrassed, and thus can experience failed 'impression management'. Gender and length of relationship appear important factors here. For example, as a relationship becomes 'routinized' couples learn to 'fit together', and to 'mutually adapt'. Although, this fitting together negates the requirement for 'private' embarrassment, it may actually increase the likelihood that the private is 'leaked' into the public domain and thus, augment the possibilities for 'reputational' embarrassment.
\end{abstract}

Key Words: sleep, unruly bodies, civilizing, embodiment, embarrassment 


\section{Introduction}

A growing body of sociological writings now exists which demonstrate an "awareness and sensitivity to the social dimensions and social significance of sleep-related matters" (Williams 2007: 325). Taylor (1993), for example, has offered a treatise on the possibilities for a sociology of sleep, Schwartz (1970) and Williams and Bendelow (1998) have proposed a Parsonian model of the rights and duties of the sleeper, Williams (2002) has debated the medicalised nature of sleep and Hislop and Arber (2003) have highlighted the gendered dimensions of the experience of sleep. Further to this, the works of authors such as Elias (1978) and Goffman (1959) can be (re)read with sleep-related matters in mind (see Williams 2007).

Central to much of this sociological literature is the suggestion that there are aspects of normativity to our dormativity (see Williams 2007). Elias (1978) argues that, whereas in medieval society it was common for many people to sleep in one room, presently the nuclear family "remains as the only legitimate, socially sanctioned enclave for [sleep] and many other human functions. Its visible and invisible walls withdraw the most 'private', 'intimate', repressively 'animal' aspects of human existence from the sight of others" (1978a: 163). This change was bound up within a historical process, which saw the emergence of "a web of interdependency" as people became more and more dependent on one another. Behaviour became more predictable (and refined) and intimate functions were secluded and hidden away within the private sphere (Vaughan 2000). In essence a "progressive socialization, rationalization and individualization of the body" (Shilling 2003: 143) occurred which saw an increase in body (self) monitoring and control.

Gleichmann (2006a) has taken up and developed these Eliasian musings on sleep. He identifies both how sleep and our knowledge of sleep has developed in interdependences, suggesting that during the Middle Ages sleep-wake cycles were undisciplined and a public matter. With the advent of industrial work, sleep became embedded within social rules and both sleep and sleep free areas developed (see also Mennell 1992: 52; Ekirch 2005; Gleichmann 2006b). Williams and Bendelow (1998), state that the sleeper has "at the very least", two duties: first, "To sleep at night and therefore to conform to the general pattern of sleep time, unless legitimate 
social circumstances, such as work arrangements dictate otherwise"; second, "To sleep in a bed, or similar device, in a private place, away from public view, in proper attire (i.e. pyjamas, nightdress etc.)" (Williams and Bendelow 1998: 182-183). For Schwartz, the requirement to sleep in private is partly because individuals feel that they have a right not to be exposed to the "creature releases" of the sleeper (1970: 492). Here Goffman's notion of "information control" is expanded. Individuals not only supervise the impressions they make, they must also shield themselves from "noxious information" emitted by others (Schwartz 1970: 493). Sleep, then, is said to be rendered "more or less legitimate depending on the circumstances and context in question" (Williams 2007: 324). Normative conventions exist and "social consequences or sanctions [are] attached to those who, for whatever reason, breach or flout these conventions" (Williams 2007: 324). For Elias (1978) these consequences and sanctions relate to the ever-lower thresholds of "shame".

These arguments linking normativity to dormativity raise at least three further, interrelated, empirical questions: First, do normative conventions require that we sleep in a private place, properly attired and away from public gazes? As Williams (2007: 316) suggests, "Elias' account of the civilizing process provides at best a limited window onto the sleeping patterns and practices of our ancestors, particularly as far as the lower ranks of society are concerned, reliant as it is on manners books". Even within Eliasian terms, things may have changed somewhat. Elias notes that as social restraint becomes second nature, rules and sanctions can become less significant (van Krieken 1998: 113). Thus, Elias himself notes that sleep is less intimate and hidden than it was last century (Fontaine 1978: 248) and Williams and Bendelow (1998) identify how at least one of the duties of the sleeper (night-time attire) is increasingly being flouted.

Second, is the social sanctioning of our dormancy limited to where and when we sleep? As Elias notes, "ladies and gentlemen did not go to bed at night - they retired. How they did it was nobody's business" (Elias 1978: 165. our emphasis). Put slightly differently, the question becomes is the, privately positioned, sleeping body ever subject to normative expectations? Analytically, this question demands a focus on both the 'private' sleeper and those who lay next to her, a heuristic separation of 
'Self' and 'Others'. With respect to the sleeper, Schwartz (1970: 486) appears to suggest that they are free of normative expectations:

We would amend Parsons by designating sleep as the fundamental tension release phenomenon, for it is emancipating not merely with respect to the social world outside of us but also (as Cooley would put it) with respect to the "society within" (1964:119-122); it admits of withdrawal from all that is subjectively as well as objectively social.

Seen in this way, sleep becomes a form of "periodic remission" where we are free to behave in ways which would breach waking normative expectations. Yet, on the other hand, we are also told that the biological dimensions of sleep "are themselves socially 'pliable', 'open' or 'unfinished"' (Williams 2003a: 172) and that the "sleeper is never completely isolated within himself, never totally a sleeper" (Merleau-Ponty 1962: 190). The manner in which we sleep may itself be dependent on 'habitus' and 'hexis'. In Bourdieusian terms, we may internalise past experiences, and aspects of bodily control, and these dispositions may function even when we are asleep. A reading of the literature on children's sleep problems would seem to point towards this. Discussing bedwetting, Dr Richard Ferber indicates how one of the suggested solutions to the 'disorder' involves "responsibility training": "you want to help your child learn to be more in charge of herself" (Ferber 1986: 173). It is suggested that the child internalise aspects of bodily control, to condition herself to "associate the feelings she has just before urinating with the need to wake" (Ferber 1986: 175: our emphasis).

With respect to 'Others', Williams' (2007) suggests that sleep related 'bad' behaviour "may not strictly speaking be considered or judged as such, given the person in question is asleep at the time and not therefore consciously aware of what they are doing or morally accountable for their 'actions"” (2007: 317). Yet, sharing a bed may blur some of the boundaries between private and public and confuse Goffmanesque notions of 'backstage' and 'frontstage'. Bed fellows may reasonably expect to be able to shield themselves from "noxious information" emitted by each other (Schwartz 1970).

The final question concerns whether factors exist which may affect commitment to, or breaching of, any normative expectations? As Crossley $(2005 ; 2006)$ suggests in his 
study of reflexive embodiment and reflexive body techniques (RBTs), normativity can run across a continuum. At one end of the continuum is the "core zone", consisting of practices which most people participate in. At the other end is the "marginal zone", consisting of bodily techniques which are rarely practiced, such as cosmetic surgery and nipple piercing. Situated between these zones is the "intermediate zone", where we find "techniques that demarcate key categorical distinctions in our society" (Crossley 2005: 28). For example, some RBTs "are gendered and some of these appear normative but others are not and/or do not" (Crossley 2006: 128). Similarly, in their discussion of commitment to a "faecal habitus" Weinberg and Williams' (2005) suggest that commitment can be mediated by such things as gender and the nature of the audience. For example, loss of control over defecation and urination may be less of an issue in settings such as care homes where staff may become used to the "abject embodiment" of their patients

This paper is concerned with addressing these three questions. Reflecting the discussion above, the paper focuses on sleep among couples and the analysis of the data centres on the concept of embarrassment. As noted above, Elias (1978) views 'shame' as a consequence of breaching normativity. For Goffman (1959), embarrassment is of fundamental social and moral significance, suggesting inconsistencies in character or discontinuities of social interaction and is intrinsically related to 'failed' impression management (Shudson 1984). Put another way, bed partners' feelings and accounts of embarrassment offer a window onto the normativity or expectations which generate this embarrassment. Following a description of the method used and our conceptual focus on embarrassment, the paper examines when (sleeping) bed partners are said to feel embarrassment and whether the potential for embarrassment is mediated by gender and couples' length of relationship. We then turn to discuss these findings in relation to the questions posed, drawing on the work on Goffman, Elias and Bourdieu.

\section{Methods}

This paper analyses data collected as part of an ESRC funded project investigating the ways in which couples negotiate their sleep. Forty couples (aged between 20 and 59, half with and half without children) were first interviewed together within their own home. Immediately following this interview each partner wore an actiwatch, a small 
watch-like device, which measures movement, and completed an audio sleep diary (see Hislop and Arber 2003; Hislop et al 2005) for a week. Partners were interviewed individually four to six weeks later. This paper analysis the couple and individual interviews, all of which were tape recorded and transcribed in full.

Two methodological difficulties can arise when focusing on sleep related embarrassment. The first relates to the inherent difficulties in asking someone to comment on a subject which they may not be aware of (i.e. sleep). Williams suggests that much of our daily life is predicated upon practices which we carry out unthinkingly (1995: 598). Following Bourdieu's writings on 'habitus', Williams suggests that "most of us, most of the time, take ourselves and the social world around us for granted; we do not think about what we do because, quite simply, we do not have to" (1995: 582). Reflexivity only tends to occur when we enter a 'field' or situation where our 'habitus', or taken-for-granted dispositions, is out of place. This is a compelling argument, but recent work by Mouzelis (2008) would seem to suggest that this lack of reflexivity might be less of an issue when examining couples. As Mouzelis (2008) argues “it is not only when a subject's habitus does not fit a field's positions that s/he becomes more reflexive. Reflexivity is also enhanced by intrahabitus tensions, by more general incongruences between dispositions, positions, and interactive/figurational structures, as well as by situations unrelated to them". Thus, individuals may be prompted towards reflexivity when interacting with others.

The second difficulty relates to the fact that there are at least two levels at which sleep related embarrassment may be evident. First, there is 'private' embarrassment when the sleeper commits acts behind closed doors (but in the presence of their bed partner). Second, there is 'reputational' embarrassment if and when talking about sleep to 'public others'. In an interview setting it may be difficult to keep these two analytic levels of embarrassment separate. For this reason the individual interview included asking participants to comment on a vignette (Barter and Renold 1999). The vignette involved an adult male sleepwalker. The interviewee was told that about once a month the male's partner would find him wandering about in his sleep and lead him back to their shared bed. The interviewer then had a three stage questioning strategy: first, questions were asked to get at issues to do with 'embarrassment' and 'being a problem'. Second, once the vignette had been fully commented on, the 
interviewer asked about other (bodily) issues and sleep disturbances, such as snoring and restless leg syndrome. Finally, the interviewer asked the respondent to relate their answers to the vignette to their actual sleeping life.

\section{Couples' sleep and the possibilities for embarrassment}

In response to the vignette, none of the respondents believed that the sleepwalker should feel embarrassed about his somnambulant behaviour. Three things appeared to be key here: first, respondents drew upon the fact that the sleepwalking was being carried out in private. Indeed, the only time they could imagine sleep walking being embarrassing was if sleep walking moved from only occurring within the bedroom into more public arenas:

Maybe he is in the nude. Suddenly discovered himself naked in the kitchen. May be he is weeing in the corner. I don't know. I don't know why he is embarrassed because I would find it funny I think, if I was sleep walking (Female, Couple 23; Individual Interview).

Second, embarrassment was negated because, to use the respondents' words, the sleepwalker was unconscious. The emphasis appears to be on Cartesian dualities, actus non facit reum nisi mens sit rea (the act does not make a person guilty unless the mind is also guilty). As one respondent claimed, "it is just some people do it don't they? I don't know the sort of reasons behind it, but I think if you are doing it unconsciously, it is nothing to be embarrassed about" (Female, Couple 12; Individual Interview). Another suggested that:

I wouldn't be embarrassed. It [sleepwalking] is like a medical condition isn't it. (Female, Couple 14; Individual Interview)

Finally, many of the respondents suggested themes similar to the following:

Male I assume they [the couple in the vignette] are married. Interviewer: Well yes.

Male: Why is he embarrassed then?

Interviewer: $\quad$ I don't know.

Male: $\quad$ You shouldn't be embarrassed if you are married should you? (Male, Couple 17; Individual Interview) 
I mean [partner] occasionally would, he hasn't done it for a while, but sort of sit up, bolt upright and start talking to me, and I would tell him the next day, and he would just say "oh I don't remember a thing about it". And that was it, "right, breakfast". So I don't think ... when you are in a relationship you look out for each other, you care for each other, and if somebody is doing something, you check each other for moles, so you know each other intimately. I don't see why he should be embarrassed. (Female, Couple 21; individual interview)

Returning to the questions posed earlier in this paper, it would seem from responses of partners to the vignette that Elias writings on sleep remain pertinent. If a sleeper is in a private space, and in an intimate relationship with his or her audience, their body appears free to do anything without risking embarrassment. As long as these conditions are met, the 'unconscious' sleeper appears exempt from waking expectations. This would seem to support Hislop's (2004) notion that (private) sleep in the presence of an intimate bed-partner is backstage, where an individual is free from role demands and expectations.

Yet, at the same time as expressing these sentiments, respondents also offered examples of times when they or their partner had felt embarrassed about some aspect of their sleep. Even within the confines of the private bedroom and an intimate partner relationship, sleeping bodies could be considered to be unruly and bed partners could experience inconsistencies in character and discontinuities of social interaction:

Well actually that sort of thing happened once to us. It was on our honeymoon. We went skiing. And [partner] got up in the middle of the night and I said "what are you doing?" and he said 'I am going down the ski lift'. And I thought "oh, bye". And he was embarrassed about it I have to say, he would probably be embarrassed if I told you this now. (Female, Couple 18; Individual Interview)

In addition, respondents suggested that the sleepwalker might feel embarrassed (simply) because he is disturbing his partner: "Perhaps he is embarrassed that he wakes her up" (Female, Couple 19; Individual Interview). What this suggests is that there are exemptions to the notion that 'unconscious', private sleepers are free to do anything without risking embarrassment.

Similar themes emerged when the respondents turned to discuss their own sleep in the interviews. For example, it was important that sleep occurred in private and sleeping bodily behaviours were more likely to be deemed unruly if they occurred in public: 
Yes I think it [snoring] does [cause embarrassment] because if someone - say we were having a girlie weekend away, knowing that you snore you sort of think, well, perhaps I ought to be in a room on my own, so that these [girlfriends] get a decent night's sleep. (Female, Couple 2; Individual Interview)

I mean laying by the pool - I did, because I fell asleep one afternoon and I woke myself up snoring, didn't I, last year, and I was really embarrassed. (Female, Couple 7; Couple Interview)

Perceived consciousness also remained important. One couple, who had known each other for just over 12 months and been married for 8 of those, suggested in response to the vignette that, "It doesn't matter if you are married. You share everything don't you?" (Female, Couple 20; Individual Interview) Yet, at the same time, the woman showed concern that she may commit acts having "biographical or reputational consequences" when asleep (Schwartz 1970: 495). As she suggested, discussing her sleep talking, "I think he [husband] just sits there listening to me, in case I drop myself in it or something; come up with the wrong name or something" (Female, Couple 20; Individual Interview). Further to this, she offered the following:
Female:
Yes, he smacks his lips and it really pisses me off.
Interviewer: How does he go?
Female: Like when somebody has eaten and they go [makes sound with lips] it is like that. When he is half asleep and half awake he will do that. And if I am asleep it wakes me up. It drives me crazy.
Interviewer: $\quad$ And have you brought that up with him.
Female: $\quad$ Yes I poke him.
Interviewer: $\quad$ You poke him....
Female: $\quad$ Yes. He knows he is doing it. And she [their 2 month old baby] is doing it as well now. It is not so bad when she does it, because she is a baby and babies are supposed to do things like that ... but a grown man. (Couple 20; Individual Interview: our emphasis)

Her male partner's response to this was to claim that he was fully asleep and had no knowledge or control over these activities. This claim to 'unconsciousness' was not agreed by both parties. However, echoing the vignette responses, there were exemptions to the notion that 'unconscious', private sleepers (with bed partners) are free to do anything without risking embarrassment. Other things intersect here, such as length and status of relationship and gender. 


\section{Length and status of relationship}

At the beginning of a relationship, partners have their own notions of normativity regarding sleeping behaviours of themselves and their partners. These are influenced by at least two things. First, there is (prior) knowledge of others' sleep. Respondents suggested that normality was determined by recourse to the behaviours of others.

I think perhaps there are more rules, for that [snoring]. Where you can do something about it. And snoring is something you can joke about. I mean sleepwalking you can joke, I suppose but snoring is a little less embarrassing. I mean everybody does it at times, I am sure. I know it happens to me, when I have had a lot to drink. I start snoring (Male, Couple 15; Individual Interview: our emphasis).

Family members and previous partners may be one of the most salient reference points available for individuals when gauging notions of normality in relation to their own and their bed partners' sleeping behaviours:

Female: $\quad$ Both my mother and father would break the world record for snoring. So you know ... my father he used to live right opposite the Gatwick Airport runway and you know on a decibel level he could compete with... Mother she is a terrible snorer. She is worse than me. She has got to be. Because I mean she has woken me up being in the next bedroom and I have had to go and wake her up.

Interviewer: Does it bother you that you snore?

Female: $\quad$ No not really. No. I mean it is not so much that I mind, I just think it is something that happens, you know, and that is it really. I mean, I don't feel embarrassed by it because I think loads of people probably snore. (Female, Couple 9; Individual Interview: our emphasis)

Second, intersecting this prior knowledge, individuals have clear notions of what makes sleeping bodies "unattractive". In some instances, they even suggested that not being unattractive during sleep should be prioritised over their own health and wellbeing:

I recently, about three or four months ago, had really bad pain in the teeth and they thought I was grinding my teeth at night. So, I have got a mouth guard. If I get really bad toothache in the day, I will wear it for say two nights, and then it will go away. So I have got a mouth guard, but generally I don't wear it that often, because it is not the most attractive or comfortable thing. (Female, Couple 11; Couple Interview: our emphasis) 
In particular, at the beginning of a couple relationship there is a complex potential for both embarrassment and conflict. Partners may come to a relationship with a shared sense of normative embodiment, leading to agreement as to when a sleeping body should feel embarrassed (upon awakening), or with differing normative views, leading to one partner feeling embarrassed when the other thinks they should not, or not feeling embarrassed when the partner feels they should. In turn, this complex potential can lead to anxiety as to whether "to display or not to display; to tell or not to tell; to let on or not to let on; to lie or not to lie; and in each case, to whom, how, when, and where" (Goffman 1963: 57).

These issues apply to the person who considers their body to be potentially 'unruly' and to the person sleeping next to the 'unruly' body. For example, one male feared that he would fart during his sleep. He therefore attempted to combat any potential embarrassment by staying awake longer than his partner (Male, Couple 14; Individual Interview). Another couple, who were both prone to talking in their sleep and other somnambulant behaviours, chose to confess to one another early in their relationship. As they suggested, though, this was possibly because they were good friends and felt comfortable sharing things, which you would not normally share with somebody for, maybe a "good six to eight months into a relationship":

Female: $\quad$ We knew each other for a long time because we worked together, so we were friends anyway, weren't we? So we were quite open with each other any way. But I think I did tell you about my sleeping, sometimes I didn't sleep.

Male: $\quad$ I think there was a lot of stuff - we were very honest with loads of stuff. Probably quite personal stuff, that you wouldn't share with somebody for maybe a good six to eight months into a relationship, because we knew each other so well that we probably shared it the first time we went out. Quite emotional and very private stuff, which we shared at that point. So we were very honest with each other, weren't we, the whole way through. (Couple 8; Couple Interview)

With respect to the partner who is sharing a bed with the 'unruly' body, one woman, who had lived through a previous marriage without gaining awareness of her own snoring, stated that: "I didn't realise I snored so badly until I lived with [new partner]" (Female, Couple 8; Couple Interview). She found this new knowledge: 
Embarrassing and like when, like he [partner] said he had to stick his elbow out to stop me rolling back [....]. .No, I mean I didn't realise I snored like that. It is horrible. (Female, Couple 8; Individual Interview)

This woman was informed that she snored 'badly', and not, as another male described his wife's snoring, "very sweet and feminine" (Male; Couple 33; Couple Interview). Similarly, another female indicated how her new partner had "told me I snored" (Female; Couple 14; Couple Interview). She found this "terrible, "horrible" and "not a nice thing" (see also Venn 2007).

Yet, as the respondents suggested, although things may remain annoying the possibilities for embarrassment relating to partner sleeping behaviours diminish as a relationship develops. As one woman suggested, "it is more relaxing when you have been together a while, you just like fit together really" (Female, Couple 14; Couple Interview). This diminishment of embarrassment, or 'fitting together', occurs principally because couples diminish the 'visibility' of the unruly body. This may happen through an 'acceptance' or an emphasis on 'mutual inconsideration'.

You have to make allowances for your partner's foibles or you know likely habits. Well, I suppose it is like everything else in a relationship, you do have to compromise to a degree. I don't suppose there is any couple in the world whose sleep patterns match exactly. So I suppose it is [a compromise] really. There has to be a certain amount of give and take. But then that is like every other aspect of a relationship, isn't it really. (Female, Couple 19; Individual Interview)

I suppose because you adapt to each other as well. So like you say you know each other's sleeping patterns, so for me, right, I am used to your snoring and your jumping out of bed, in the same way that you are used to my twitching and getting up and going to the loo. (Female, Couple 11; Couple Interview)

Following Weinberg and Williams (2005), then, the longer the duration of the relationship the greater the potential that couples 'routinize' their experience of other's bodily functions. 'Invisibility' may also result from particular strategies. For example, one partner may go to bed earlier to avoid the impact of the other's snoring (cf. Female, Couple 10). Similarly, one (snoring) partner may consciously make sure that the other is asleep before going to bed (cf. Male; Couple 10). Couples may also 'normalize' or 'neutralize' potentially embarrassing events. For example, one female offered the following narrative: 
Once I woke up [and] I was standing in the middle of the bed and you picked me up. I said "what the hell are you ..." first of all he dragged me across the bed.

"What are you doing, what are you doing?" - because he will talk to you completely, like he is wide awake. So I said 'oh, I, what are you doing?' [He said] "You have got to get out, you have got to get out". So, of course, I start panicking thinking he is awake. I am like 'oh my God, maybe the house is on fire', so I am, like, sniff, sniff, sniff. I can't smell anything no. Then I realised he was asleep because he has done it a few times. So I said "no, no. I am going to stay here" and managed to wrestle my arms off him. So he kneels down on the bed, picks me up and carries me out the room. "What are you doing? You have got to get out, you have got to get..." And he just wouldn't... [let her go] normally if I talk to him and say, like, "I, I, you are asleep, will you wake up?" But this time he wouldn't, and the only way I managed to wake him up was to actually slap him round the face, but by which point he dropped me on the wooden floor, got back into bed and started snoring. (Female, Couple 11; Couple Interview)

To an outside observer, this may appear to be a situation deserving serious attention: a 'sufficiently unusual' nocturnal behaviour which warrants the imposition of sanctions and perhaps should prompt embarrassment on the part of the 'offender'. This is especially so when it is considered that within the follow up interview, the woman stated that during the period between the couple and individual interview, "he started shouting in his sleep. So literally each night he woke me up at least four or five times a night and so I came into work Monday and somebody said to me "God you look really tired' and I said 'I haven't slept for three nights"' (Female, Couple 11; Individual Interview). However, she also suggested that, in some respects, she was actually 'flattered' by the male's behaviours. As she suggested, under different (waking) circumstances his behaviour would be deemed normal, if not 'heroic': "It is actually quite flattering because you think you were trying to save me from being crushed. It was most bizarre" (Female, Couple 11; Couple Interview). As Weinberg and Williams' (2005) note, it is not so much the action itself which provokes embarrassment, but the reaction it gets from other people.

To summarize, the couples within the present study emphasized how sleeping bodies should never provoke embarrassment, providing that the sleeper was 'unconscious', sleep was occurring behind closed doors and only in the presence of an intimate other. However, caveats to this become apparent. At the beginning of an intimate relationship couples do feel waking embarrassment about unruly bodily acts committed whilst they were asleep and attempt to undertake 'impression management'. As the relationship becomes 'routinized' the possibilities for 
embarrassment in relation to their bed partner diminish as couples learn to 'fit together', and to 'mutually adapt'. All this, however, relates to 'private' embarrassment; to acts committed solely in the presence of bed partners. There is also the potential for 'reputational' embarrassment if and when sleep is talked about, or bodily acts committed while sleeping become known, to 'public others'. This paper now addresses this issue.

\section{Public, private and the intersection of gender}

Venn (2007) suggests that the way that snoring is (un)contested within couples is influenced by three factors: women's perception that snoring is unfeminine, concern about men publicly revealing that their female partners snore thus moving the discreditable to the discredited and women's subjugation of their own sleep needs to that of their partner. Venn's (2007) arguments have some resonance with the present findings. Women seemed especially embarrassed when the unruly nature of their sleeping bodies was mentioned to 'public others':

Interviewer: $\quad$ Does he tell other people that you snore?

Female: $\quad$ Yes. He is horrible. (Female, Couple 8; Individual Interview)

Men on the other hand were much more 'matter-of-fact' about public discussions of their sleeping bodies (see also Venn 2007). Men appeared to emphasise (both privately and publicly) their unconsciousness and lack of control while asleep as a means of negating embarrassment: "I don't remember any of it really so... I don't remember things in the morning" (Male, Couple 11; Couple Interview), "I don't know I do it. It doesn't wake me up. I don't have a sore jaw in the morning or anything like that. So I am oblivious to it happening” (Male, Couple 26; Individual Interview).

Our data suggests that there are two parallel strands to the link between normativity and dormativity. On one level (the private) embarrassment is diminished over time as the couple relationship develops. On another level (the public/reputational) the potential for embarrassment continues to be strong; especially for women. For example, one woman claimed that “women are more conscious of the other person's feelings as well and not embarrassing him" (Female, Couple 8; Individual Interview). When responding to the vignette many female respondents showed a (gendered) awareness of why the sleepwalker may feel embarrassed: 
Men like to feel that they are in control don't they ... [sleep problems] bring connotations of ageing and sort of helplessness perhaps, and he doesn't want his wife to see him sort of ... (Female, Couple 12; Individual Interview)

I don't think men like feeling helpless in a lot of situations and especially if he is not conscious about it. It is a very unconscious thing and it might be quite disturbing for him. (Female; Couple 15, Individual Interview)

I don't know why he would be embarrassed though. Maybe it is the thought that he is not in control. (Female, Couple 17; Individual Interview)

It could be something to do with, I don't know, men aren't supposed to sleepwalk or something, a masculine thing, I don't know. (Female, Couple 13; Individual Interview)

Women's increased 'awareness', or 'consciousness', of other's (i.e. men's) feelings may result in women undertaking greater preventative work to stop their partner feeling embarrassed (publicly or privately). It may also be a reflection of women's own discomfort 'in' their own bodies. As Crossley suggests, discussing the work of Young, women are positioned as objects of perception. This affects a woman's manner of being-in-the-world; 'women cannot be comfortable 'in' their bodies in the same way as men are, [Young] argues, and cannot enjoy the same degree of freedom of movement, because their bodies are objectified in a patriarchal culture and are experienced as such' (Crossley 2001: 158).

As well as the dominant themes already outlined within the couples' narratives, several other factors deserve mention. First, there was an emphasis on frequency within several of the narratives. As Weinberg and Williams (2005) suggest, embarrassment and shame are less likely to be reported in relationships that had become routinized. In these relationships a single, 'unruly', event would probably not outweigh other aspects of a primary relationship (see also Venn 2007). High frequency of occurrence, however, can itself be a threat to routinization. Similarly, the respondents' discussions of bodily behaviours focused largely on sleepwalking and snoring. None of the couples defecated in beds or suffered from enuresis (bed wetting) or nocturia (or at least none said they did). However, respondents did suggest that severity of incidents could also be a threat to routinization.

Second, bodily changes appear important. For example, 
I would say I am a little bit embarrassed that I snore anyway. Because I didn't used to, and I never really associated it as a desirable trait, really. So, on that sort of level I am kind of embarrassed I guess. (Male, Couple 12; Individual Interview: our emphasis)

These bodily changes can relate to new events arising after the relationship has become routinized or an increase in frequency or severity of the behaviour.

\section{Discussion, conclusions and caveats}

Drawing upon qualitative data from 40 couples (aged between 20 and 59), this paper has suggested that, if a sleeper is considered to be 'unconscious', in a private space, and in an intimate relationship with his or her audience, bodies appear free to break the normative boundaries of (waking) acceptable/civilized behaviours without risking embarrassment. Yet, despite appearances, breaking these boundaries does have potential for biographical or reputational impacts, and audience anger, resentment and conflict. This, however, is a complex potential mediated by things such as prior normative expectations, length and status of relationship and gender. At the beginning of an intimate relationship couples do feel waking embarrassment about certain, 'unruly', bodily acts committed whilst they were asleep and attempt to undertake 'impression management'. As the relationship becomes 'routinized' couples learn to 'fit together', and to 'mutually adapt'. Although, this fitting together negates the requirement for 'private' embarrassment, the potential for public/reputational embarrassment remains strong (especially for women). Further to this, private embarrassment, anger and resentment are minimised, but can be (re)provoked by bodily changes and changes in frequency.

This paper addressed three questions; First, do normative conventions require that we sleep in a private place, properly attired and away from public gazes? Second, is the social sanctioning of our dormancy limited to where and when we sleep, or is how we sleep also socially sanctioned? Finally, are there factors which affect commitment to, or breaching of, any normative expectations? With respect to the first question, Elias (1978) does appear to be correct: A 'progressive socialization, rationalization and individualization of the body' (Shilling 2003: 143) has occurred which has seen sleep removed to the private domain. In Goffmanesque terms the sleeper removes 
themselves into the private domain to ensure 'information control' and to respect others' right not to be exposed to the 'creature releases' of the sleeper (Schwartz 1970: 492). The couples within the present study all emphasised the importance of location of sleep when discussing embarrassment. The sleepwalker may feel embarrassed if found wandering outside of the confines of the private bedroom and the snorer may feel (more) embarrassed if witnessed at a 'girlie weekend' or 'laying by the pool'.

The second question posed involves investigating whether others view the sleeper as not consciously aware of what they are doing or morally accountable for their 'actions', as well as the extent to which sleep equates to 'depth disappearance' (Leder 1990) or a difference between waking and sleeping life. The couples within this study clearly see a demarcation between sleeping and waking bodies. The emphasis on consciousness within many of the narratives suggests that, for them, sleep is seen as 'periodic remission'. Yet, for some, the (sleeping) body remains a source of (waking) embarrassment even when it is behind closed doors. Both Goffman and Bourdieu offer assistance here. In Goffmanesque terms, the relationship between sleep related bodily behaviours and (waking) embarrassment suggests that for these couples the sleeper may not necessarily be situated within an 'interaction membrane' (although embarrassment will not be felt until awakening) and sleep may not remove the need to perform "social problems prevention work" (cf. Weinberg and Williams 2005). Put another way, our data on couples' sleep calls into question the notion that the coupled sleeper is 'backstage'; where people are generally said to be free to "engage in a range of 'uncivilised' behaviours, from nose picking to burping, farting and belching" (Williams and Bendelow 1998: 43). Sharing a bed may blur the divisions between public and private, and 'front' and 'back' stage. My body may have more scope to be unruly when my bed partner is asleep.

Notions of (sleeping) 'habits', learnt from parents, and normative expectations, also resonate somewhat with Bourdieu's writings and seem to suggest that sleep is conceived through habitus and modes of bodily hexis (cf. Williams 2003b). The fact that the potential for 'private' embarrassment is strongest at the beginning of a relationship also resonates with Mouzelis' (2008) argument that “an actor's dispositions might be in conflict not only with a field's system of positions but also 
with its figurational structures." Seen in this way, couples bring their sleep habitus to the beginning of a relationship and where each partners' habitus does not match, they are brought into conflict with one another. The lack of discussion of nocturnal defecation or urination also points tentatively towards a 'sleep habitus'. Within the present study, the lack of these events, and any "abject embodiment", may reflect a successful sleep habitus and the ability to "associate the feelings she has just before urinating with the need to wake". A full exploration of this is beyond the remit of the present study, but seems worthy of further investigation.

We can summarise these arguments further through answering the final question addressed in this paper. To borrow Crossley's (2006) terminology, these relate to the relationships between 'core' and 'intermediate' aspects of bodily, sleep related, normativity. The 'core' includes the assumption, shared by all respondents, that sleep should occur in private and behind closed doors. However, as a couple relationship develops (private) sleeping bodies do appear to have greater freedom to behave in an 'unruly' manner without fear of ramifications or sanctions. Even within intimate relationships, however, women show greater commitment to the notion that once behind closed doors how people 'do' sleep is 'nobody's business' (Elias 1978: 165. , our emphasis). This demonstrates continued occurrence of gendered 'normativity'. It is possible that as a relationship (and bodily behaviours) becomes 'routinized', men and women engage with differing modes of (sleep) embodiment. Men may be 'freer' to move from the 'normative' to the 'pragmatic' as 'intimacy' develops. Women's relationship with sleep, on the other hand, arguably remains bound up within 'normative' modes of embodiment. This rooting within normative modes of embodiment may reflect the fact that women 'are made to feel uncomfortable in their bodies, just as Sartre's peeping tom is, because they feel themselves captured and caught in the gaze of others' (Crossley 2001: 158). 


\section{Acknowledgements}

The authors would like to thank Vicky Vaughan for assisting with some of the data collection, and Andy King, Jo Moran-Ellis and the Editors of this special edition for useful pointers, discussions and comments. Thanks must also go to the numerous men and women who gave up their time to participate in this research. This study was funded by Economic and Social Research Council grant RES-000-23-0268. 


\section{References}

Barter, C. and Renold, E. (1999) The Use of Vignettes in Qualitative Research Social Research Update Issue 25: Summer

Crossley, N. (2001) The Social Body: Habit, Identity and Desire London: Sage

Crossley, N. (2005) Mapping Reflexive Body Techniques: On Body Modification and Maintenance Body \& Society 11(1):1-35

Crossley, N. (2006) Reflexive embodiment in contemporary societies London: Open University Press

Ekirch, R. (2005) At day's close: Nights in times past London: Orion Publishing Elias, N. (1978) The Civilizing Process, Oxford: Blackwell.

Ferber, R. (1986) Solve Your Child's Sleep Problems: A Practical and Comprehensive Guide for Parents London: Dorling Kindersley Publishers Ltd

Fontaine, S. (1978) The civilizing process revisited: interview with Norbert Elias Theory and Society 5(2): 243-253

Gleichmann, P. (2006a) Schlafen und Schlafräume in H-P Waldhoff (ed) Soziologie als Synthese: Zivilisationstheoretische Schriften über Architektur, Wissen und Gewalt Wiesbaden: VS - Verlag für Sozialwissenschaften,

Gleichmann, P. (2006b) Nacht und Zivilisation: Wandlungen im Erleben der Nacht in H-P Waldhoff (ed) Soziologie als Synthese: Zivilisationstheoretische Schriften über Architektur, Wissen und Gewalt Wiesbaden: VS - Verlag für Sozialwissenschaften, Goffman, E. (1959) The Presentation of Self in Everyday Life, London: Penguin. Goffman, E. (1997/1963) Stigma: Notes on the management of spoiled identity in C. Lemert and A. Branaman (eds) The Goffman Reader London: Blackwell Publishing Hislop, J. (2004) The social context of women's sleep, Surrey University: Unpublished $\mathrm{PhD}$ thesis.

Hislop, J. and Arber, S. (2003) 'Sleepers wake!' The gendered nature of sleep disruption among mid-life women, Sociology 37(4): 695-711.

Hislop, J., Arber, S., Meadows, R. and Venn, S. (2005) Narratives of the night: the use of audio diaries in researching sleep, Sociological Research Online, 10(4): <http://www.socresonline.org.uk/10/4/hislop.html>.

Leder, D. (1990) The Absent Body Chicago: University of Chicago Press. Mennell, S. (1992) Norbert Elias: an introduction Dublin, University College Dublin Press 
Merleau-Ponty, M. (1962) Phenomenology of Perception London: Routledge and Kegan Paul.

Mouzelis, N. (2008) Habitus and Reflexivity: Restructuring Bourdieu's Theory of Practice Sociological Research Online 12(6)

Schwartz, B. (1970) Notes on the sociology of sleep, The Sociological Quarterly 11(4):485-499.

Shilling, C., (2003), The Body and Social Theory ( $2^{\text {nd }}$ edition), London: Sage Publications.

Schudson, M. (1984) Embarrassment and Erving Goffman's idea of human nature.

Theory and Society: Renewal and Critiques in Social Theory, 13, 633-648.

Taylor, B. (1993) Unconsciousness and Society: The Sociology of Sleep International Journal of Politics, Culture and Society, 6 (3) 463-471

Van Krieken, R. (1998) Norbert Elias London: Routledge

Weinberg M.S. and Williams C.J. (2005) Fecal Matters: Habitus, Embodiments, and Deviance, Social Problems, 52(3), 315-336.

Williams, S., J. (1995) Theorizing class, health and lifestyles: can Bourdieu help us? Sociology of Health and Illness, 17, 577-604

Williams, S., J. (2002) Sleep and Health: Sociological reflections on the dormant society Health: An Interdisciplinary Journal for the Social Study of Health,Illness and Medicine 6(2):173-200

Williams, S.J. (2003a) Liminal bodies? Sleep, death and dying. In Williams, S.J., Birke, L. and Bendelow, G. (eds) Debating Biology: Sociological Reflections on Health, Medicine and Society London: Routledge.

Williams, S., J. (2003b) Medicine and the body. London: Sage.

Williams, S., J. (2007) The social etiquette of sleep: some sociological reflections and observations Sociology 41(2):313-328

Williams, S. J. and Bendelow, G. (1998) The lived body: sociological themes, embodied issues, London: Routledge.

Vaughan, B. (2000) The civilising process and the Janus-face of modern punishment Theoretical Criminology 4(1):71-91

Venn, S. (2007) 'It's ok for a man to snore' The influence of gender in addressing sleep disruption in couples Sociological Research Online 12(5) 